\title{
Book Review: Teaching International Students
}

\section{Carroll, J. \& Ryan, J. (Eds.). (2005). Teaching international students: improving education for all. London \& New York: Routledge.}

Reviewed by Barbara Harold (Zayed University, Dubai).

Teaching International Students is the twentieth book in a series edited by Professor James Wisdom and published by SEDA (Staff and Educational Development Association), a British group which supports and encourages developments in teaching and learning in higher education. The editors write or contribute to nine of the sixteen chapters. While the bulk of the contributors are based in Australia, other contributors bring perspectives from Hong Kong, Europe and the UK. The writers call on a range of experience with international students and bring views from teaching, learning and administration in higher education. Short biographies of the contributors are shown at the beginning of the book and are helpful in establishing their experience and credibility.

The introductory chapter sets the context for the book by providing data about the increase of international students in English speaking countries and outlining the need for Western universities to meet the challenge of providing for the needs of teachers and students in an increasingly diverse higher education context. The editors challenge the deficit view that many lecturers hold of international students and state their basic premise which is that "by adopting approaches that are inclusive of international students [teachers] will also be more generally inclusive of a broader range of learners" (p. 6). Having set the context the editors go on to describe the structure of the book and to counter some common fears expressed in discussions about pedagogy for international students e.g. that differential treatment will result in 'lowering of standards' or 'unfair advantage'. They argue that rather than see international students as part of commercially-driven ( and sometimes unwelcome) change to the academic environment there are benefits for teachers and students alike by viewing international students as "bearers of alternative knowledge, perspectives and life experiences" (p.9).

The book is structured in three sections. The first, entitled 'Cultural migration and learning' comprises four chapters and focuses on issues of 'cultural' capital and its relationship with 'academic' culture. Within a framework of socio-cultural theory, chapter 2, Maximizing international students' 'cultural capital', discusses the ways in which learning contexts can be created to help international students adjust more easily to an unfamiliar academic environment. The following chapter, Gathering cultural knowledge, deals in some critical depth with theories and concepts of 'culture', examines some myths and stereotypes and concludes by suggesting that teachers need to critically aware of their own culture and to help their international students develop a meta-cultural sensitivity that will provide them with the means to assess different cultures, including the host culture, with understanding and patience. In this way the students can also assist their teachers to develop a similar understanding - not a simple 'gathering of facts' about the others' culture, but rather a changed orientation towards them. Chapter 4, Strategies for becoming more explicit, focuses on very practical strategies that will allow students to adjust, adapt and be successful in their new environment. It provides examples of common misunderstanding and problems between teacher and student and suggests strategies to overcome or minimize these. The suggestions are mostly concerned with explicitness and clarity in language, instruction and teacher-student relationships. The final chapter in Part One, Lightening the load: Teaching in English, learning in English, identifies the nature and source of misconceptions about the

Harold, B. (2008). Book Review: Teaching International Students. Learning and teaching in higher education: Gulf perspectives 5(1). http://www.zu.ac.ae/lthe/lthe05_01_07_harold.htm

page 52 
English competency of international students. It also describes the linguistic 'shock' encountered by many students with basic English skills who are suddenly immersed in a sophisticated language environment and suggests specific strategies that teachers and university management can use to get students through this stage (e.g. learning centers, handouts, summary notes, glossaries of terms and the like).

Part Two of the book moves into the area of methodologies and pedagogies and provides further useful classroom strategies to enhance the learning of international students. It is the largest section of the book and contains 6 chapters. Chapter 6 , Building intercultural competencies, is one of the longest and provides a wide variety of teaching methods related to writing, speaking, thinking, and collaboration. It also has some useful comments about what constitutes 'cheating' in cross-cultural contexts and how to deal with it. The seventh chapter, Writing in the international classroom, continues the practical emphasis with methods to guide international students towards success in writing. It has a valuable commentary about plagiarism, discussing it in terms of language acquisition, ideas, culture and use of sources. Chapters 8 and 9, Fostering intercultural learning through multicultural group work and Multicultural groups for discipline-specific tasks: can a new approach be more effective?, both deal with the topic of multi-cultural grouping and contain valuable advice about setting up groups, providing guidance about group processes, designing appropriate tasks and assessment of group work. The key difference between these chapters is that the first gives a more general overview of group work, while the second relates it to specific disciplinary contexts. These two chapters could perhaps have been written as one as there is some overlapping content in each. The tenth chapter in Part Two, Improving teaching and learning practices for international students, deals with key issues in curriculum content and design, the learning environment, content delivery, student involvement and assessment. Once again the content is practical and the chapter also raises a range of questions that teachers could ask themselves as they review their teaching and assessment methods. The final chapter, Postgraduate supervision, identifies common problems and provides excellent advice for effective supervision of postgraduate research.

The third section of the book looks more broadly at issues in tertiary curriculum and what we teach and research. Chapter 12, Internationalization of the curriculum: An institutional approach, discusses the issues from an institutional level and describes how the curriculum might be 'internationalized' to provide more relevance for students crossing global boundaries in their study and research. The following chapter, Internationalization of the curriculum: Teaching and learning - narrows the focus to the classroom and provides practical suggestions about course design, content teaching activities and assessment. Chapter 14 is a short piece that highlights benefits for the generation of knowledge, the institution, and the supervisor from the development of strong cross-cultural research programs. Interestingly there is no comment on the benefits for students although this may perhaps be inferred from sections of the chapter. The following chapter, Collaborating and co-learning, is an important one that discusses ways in which teachers can collaborate in teaching teams, departments and the university as a whole to support and enhance teaching and learning experiences for international students. The final chapter in this section, The student experience: Challenges and rewards, reminds readers of the culture shock, language shock and academic shock faced by many international students and concludes with the benefits and rewards of working with them to overcome these issues.

Each chapter is followed by a list of references but there is no summary of references at the end of the book. There is a comprehensive index covering a range of topics to help the reader find particular information. This book would make a valuable addition to the bookshelf of any tertiary teacher who wishes to enhance teaching strategies and student learning.

Harold, B. (2008). Book Review: Teaching International Students. Learning and teaching in higher education: Gulf perspectives 5(1). http://www.zu.ac.ae/Ithe/Ithe05_01_07_harold.htm 
Although this book is written for tertiary teachers in their 'home' culture who work with students from different cultures its messages have some important resonance for expatriate teachers in the Middle East who are working with students in their home culture. Many of the problems and issues described in the book work both ways as essentially they address the needs of both students and teachers in cross cultural contexts. As the authors note early in the book they are concerned about the teaching-learning process in general as well as specific terms and much of the content contains valuable advice for improving the educational experience in general. In an increasingly globalized world facing international tensions and pressures, this book provides a refreshing and valuable perspective on how to improve cross-cultural understanding and tolerance through higher education. 